\title{
CONTAMINAÇÃO POR CHUMBO NA SERRAPILHEIRA DO PARQUE NACIONAL DA TIJUCA - RJ.
}

\author{
Rogério Ribeiro de Oliveira (1) \\ Luiz Drude de Lacerda (2)
}

\begin{abstract}
RESUMO - As matas formadoras do Parque Nacional da Tijuca, Rio de Janeiro, apresentaram em sua serrapilheira um teor médio de chumbo de $16,2 \mu \mathrm{g} / \mathrm{g}$ ao longo de um ano. A entrada do metal no sistema via queda da serrapilheira foi de $140 \mathrm{~g} / \mathrm{ha} / \mathrm{ano}$. $\mathrm{O} \mathrm{Pb}$ atinge o sistema florestal pela deposiçāo atmosférica, e tem origem provável na queima de combustíveis (gasolina e petróleo).
\end{abstract}

\begin{abstract}
Analysis of the litter layer of the Tijuca National Park rainforest revealed an average annual lead concentration of $16.2 \mu \mathrm{g} / \mathrm{g}$. Rate of lead in the litter fall was $140 \mathrm{~g} / \mathrm{ha} / \mathrm{yr}$. Lead enters the forest ecosystem by way of the atmosphere, gasoline usage and petroleum combustion being the most probable causes.

Key words: litter, lead, Tijuca National Park.
\end{abstract}

\section{Introdução}

A entrada de nutrientes para a vegetação através de detritos vegetais depositados no solo consiste em importante fonte de sustentação de sistemas florestais tropicais. A quantificação e análise do material orgânico decíduo são também de grande interesse para o estudo da ciclagem mineral, uma vez que a transferência de nutrientes da vegetação para o solo se dá através da decomposição desse material.

A camada de serrapilheira consiste em um compartimento acumulador onde todos os elementos bióticos e abióticos do ecossistema estão potencialmente representados, sendo portanto sua constituição mineralógica um reflexo do sistema como um todo. Assim sendo, sua resposta à entrada de poluentes é representativa de todos os demais compartimentos, pelo menos no aspecto qualitativo.

Dados sobre a concentração de nutrientes na serrapilheira em formações florestais brasileiras podem ser encontrados em diversos trabalhos, ainda que sejam relativamente exíguas as informações sobre o aporte de elementos oriundos da poluição atmosférica na mesma. Algumas exceções são Domingos et al. (1986), Lopes et al. (1986), Silva Filho e Ovalle (1984), Struffaldi-De Vuono et al. (1984) e Struffaldi-De Vuono e Marzolla (1984).

Rodeadas pela cidade do Rio de Janeiro, as matas que compōem o Parque Nacional da Tijuca estão sujeitas a efeitos antrópicos diretos e indiretos, cuja magnitude de impacto é muitas vezes desconhecida. Silva Filho e Ovalle (1984) documentaram a ocorrência de chuva ácida na região da Floresta da Tijuca, como conseqüência da alta carga de contaminantes lançada na atmosfera da cidade do Rio de Janeiro. Trindade et al. (1981) encontraram altas concentrações de diversos poluentes, incluindo metais pesados, em amostras

(1) - Divisão de Dinâmica de Ecossistemas, Departamento de Estudos e Projetos, FEEMA. Rua Fonseca Telles, 121/1708, CEP 20940 - RIO DE JANEIRO - RJ.

(2) - Programa de Pós-Graduaçâo em Geoquímica, Instituto de Química, UFF. 
de ar coletadas próximo à região do Parque Nacional da Tijuca. Entretanto, até o momento nenhum trabalho estudou o destino destes poluentes nos ecossistemas florestais que ocorrem na cidade do Rio de Janeiro, dos quais a Floresta da Tijuca é o mais importante. A presente contribuição ocupa-se da deposição atmosférica do chumbo, detectado na serra. pilheira, em uma área florestal típica do Parque Nacional da Tijuca.

\section{Materiais e Métodos}

A área de estudos está localizada no interior do Parque Nacional da Tijuca (2257'9" $S$ e $43^{\circ} 18^{\prime} 3^{\prime \prime}$ W. Gr.), situado no município do Rio de Janeiro. Segundo o esquema proposto por Budowski (1965) as matas da região caracterizam-se como secundárias tardias.

O clima da região é definido como tropical de altitude (Coelho Netto 1985), com precipitações da ordem de $2500 \mathrm{~mm} / \mathrm{ano}$, sendo a temperatura média mensal compreendida entre $15^{\circ}$ e $30^{\circ} \mathrm{C}$, com média anual de $21^{\circ} \mathrm{C}$. A geologia é caracterizada pela predominância de biotita-gnaisse e granitos de idade Pré-Cambriana. Os solos da área caracterizamse por manto intemperizado pouco espesso nos trechos mais declivosos, atingindo alguns metros nos depósitos de encosta. São na maioria latossolos, com pouca diferenciação entre os horizontes (Coelho Netto 1985).

A serrapilheira foi coletada no período de 14 de novembro de 1983 a 13 de novembro de 1984, com a utilização de 30 coletores, construídos e operados segundo as recomendaçōes de Medwecka-Kornas (1970) e Proctor (1983). O local onde estavam instalados os coletores é distante $1,4 \mathrm{~km}$ em linha reta da estrada mais próxima. O material foi coletado semanalmente, separado nas suas diversas fraçōes, seco em estufa e pesado. Posteriormente este era reduzido a pó para ulterior análise química. A digestão das amostras para extração dos elementos dos tecidos foi feita com o uso do método de Miyazama et al. (1984). O extrato ácido foi analisado em espectrofotômetro de absorção atômica convencional. Todas as amostras foram analisadas em triplicata e os resultados apresentados sob a forma de média e desvio padrão. Testes paramétricos de Pearson foram utilizados nas análises de correlação entre os teores de $\mathrm{Pb}$ na serrapilheira e no ar atmosférico, bem como entre o teor deste alemento na serrapilheira e o regime pluviométrico (Snedecor $\&$ Cochran 1967).

Os dados de poluição atmosférica foram fornecidos pela Divisão de Planejamenc Ambiental (DIPLAN 2.1), do Departamento de Estudos e Projetos da Fundação Estadual de Engenharia do Meio Ambiente e referem-se à estação de Santa Tereza, que é a mais próxima do local de estudos (cerca de $5 \mathrm{~km}$ em linha reta). Os dados pluviométricos foran estraídos de Silva Filho e Ovalle (1984).

\section{Resultados e Discussão}

O total de serrapilheira produzido ao longo de um ano foi de 8,9 ton/ha. Deste total, as folhas representaram $74,0 \%$, os galhos $12,8 \%$, os elementos reprodutivos (flores, frutos e etc.) $8,0 \%$ e os resíduos $5,2 \%$ (Oliveira 1987 ).

A análise química da serrapilheira depositada nas matas do Parque Nacional da Tijuca revelou uma concentração média de chumbo de 16,2 $\pm 5,4 \mu \mathrm{g} / \mathrm{g}$ de peso seco, com um mínimo de $10 \mu \mathrm{g} / \mathrm{g}$ e um máximo de $25 \mu \mathrm{g} / \mathrm{g}$.

A entrada de chumbo no sistema solo-planta atingiu $140 \mathrm{~g} / \mathrm{ha} / \mathrm{ano}$ (Tabela 1). Este total, se comparado a outros metais, é superior ao do cobre $(110 \mathrm{~g} / \mathrm{ha} / \mathrm{ano})$ e inferior ao do zinco (630 g/ha/ano) ocorrentes na serrapilheira (Oliveira 1987). Tratam-se de valores relativamente altos, levando-se em consideração a distância do local de coleta de focos de poluição. 
Tabela 1 - Deposição de $\mathrm{Pb}, \mathrm{Cu}$ e $\mathrm{Zn}$ no solo via serrapilheira no Parque Nacional da Tijuca de 14/11/1983 a 13/11/1984 (em g/ha). Os valores de Cu e $\mathrm{Zn}$ foram extraídos de Oliveira (1987).

\begin{tabular}{lrrl} 
MESES & $\mathrm{Pb}$ & $\mathrm{Cu}$ & $\mathrm{Zn}$ \\
\hline Dezembro & 19,3 & 11,6 & 64 \\
Janeiro & 9,2 & 6,5 & 48 \\
Fevereiro & 10,7 & 11,9 & 59 \\
Março & 4,1 & 3,9 & 29 \\
Abril & 13,2 & 6,2 & 33 \\
Maio & 8,7 & 8,6 & 42 \\
Junho & 10,2 & 9,7 & 50 \\
Julho & 17,4 & 15,3 & 71 \\
Agosto & 10,8 & 7,3 & 54 \\
Setembro & 12,6 & 6,9 & 46 \\
Outubro & 13,5 & 6,9 & 45 \\
Novembro & 14,1 & 11,8 & 88 \\
\hline TOTAL & 143,8 & 106,6 & 629
\end{tabular}

Esses dados são bastante superiores à concentração de $2,5 \mu \mathrm{g} / \mathrm{g}$ de peso seco encontrada por Warren e Delavaut (1962) em folhas de plantas lenhosas de clima temperado e inferiores aos valores obtidos no Panamá por Golley et al. (1968), $39 \mu \mathrm{g} / \mathrm{g}$, correspondendo a uma deposição de $440 \mathrm{~g} / \mathrm{ha}$ de $\mathrm{Pb}$ via serrapilheira. Struffaldi-De Vuono et al. (1984) encontraram concentração de chumbo no material decíduo muito próxima ao resultado ora obtido. No entanto, a serrapilheira analisada por aqueles autores foi coletada a uma distância inferior a $1200 \mathrm{~m}$ de uma fonte poluidora pontual, o que não é o caso do Parque Nacional da Tijuca.

A figura 1 mostra a variação do teor de chumbo na serrapilheira ao longo do ano, que permaneceu relativamente constante. Não foi ve.ificada correlação estatística significativa entre o regime pluviométrico e a concentração de chumbo na serrapilheira $(r=0,1)$ nem tampouco entre esta e o teor de chumbo no ar atmosférico $(r=0,09)$ - (Fig. 2). Tal fato pode estar indicando a deposição de chumbo por meio de outros eventos atmosféricos (neblina, orvalho ou deposição seca).

Acerca da origem do $\mathrm{Pb}$ na serrapilheira, a maior evidência é que este é proveniente do chumbo tetra-etila utilizado como anti-detonante na gasolina de veículos automotores. Embora o chumbo tenha diversas utilizações industriais, é no seu uso como aditivo que se verifica a sua maior fonte poluidora da atmosfera (W.H.O. 1977). Sendo a sua dispersão principalmente pelo ar atmosférico, sua deposição se dá com maior intensidade nas zonas metropolitanas dos centros urbanos e áreas circunvizinhas (Snyder 1967), como é o caso do Parque Nacional da Tijuca. Clayton (1972) afirma que os dosséis florestais constituemse em eficientíssimos coletores de gases e aerossóis, o que contribui para elevar a deposição de chumbo no sistema.

A relativa constância do teor de chumbo no material decíduo não associado significativamente a mudanças no teor daquele metal no ar atmosférico ou no regime pluviométrico, permite supor que o elemento tenha uma localização intratissular. Acumulado nas 
comunidades vegetais ao longo do tempo, sua permanência seria assegurada por uma constante ciclagem e por novos aportes oriundos da poluição atmosférica, uma vez que sua solubilidade na água ou por compostos orgânicos de origem vegetal é muito baixa (W.H.O. 1977).

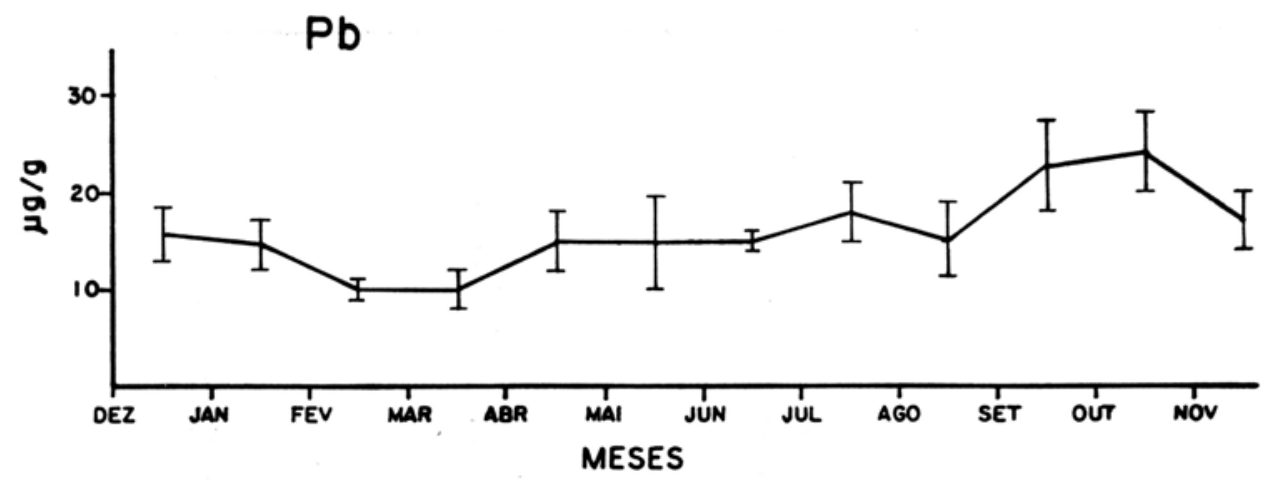

Figura 1 - Concentração de chumbo na serrapilheira ( $\mu \mathrm{g} / \mathrm{g}$ de peso seco).

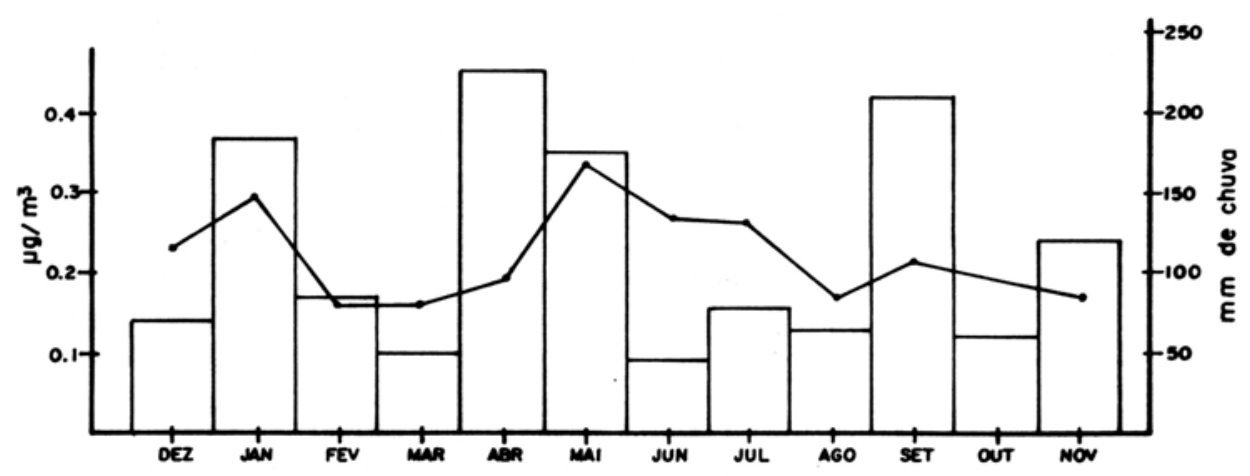

Figura 2 - Histograma de pluviosidade (Silva Filho \& Ovalle, 1984) e gráfico de concentraçăo de chumbo no ar (DIPLAN/DEP, com. pes.). 


\section{Referências Bibliográficas}

BUDOWSKI, V. 1965. Distribution of tropical american rain forest in the light of successional. Turrialba 15: 40-42.

CLA YTON, J.L. 1972. Salt spray and mineral cycling in two California coastal ecosystems. Ecology 53: 74-81.

COELHO NETTO, A.L. 1985. Surface hydrology and soil erosion in a tropical mountainous rainforest drainage basin, Rio de Janeiro. Phd thesis. Katholieke Universiteit Leuven.

DOMINGOS, M., POGGIANI, F. $£$ DE VUONO, Y.S. 1986. Poluição atmosférica em trecho de mata atlântica: III - Ciciagem de nutrientes na água de chuva e folhedo. In: XXXVII Congresso Nac. Bot. Resumos p. 93.

GOLLEY, F.B., MC GINNIS, J.T., CLEMENTS, R.G., CHILD, G.I. £ DUEVER, M.J. 1978. Ciclagem de minerais em um ecossistema de floresta tropical úmida. Ed. da Univ. São Paulo. São Paulo.

LOPES, M.I., DE VUONO, Y.S., GUIDA, A.M. £ DOMINGOS, M. 1986. Poluição atmosférica em trecho de mata atlântica: 1 Algumas propriedades químicas do solo. In: XXXVII Congresso Nac. Bot. Resumos p. 93.

MEDWECKA-KORNAS, A. 1970. Litter Production. In: Methods of Study in Soil Ecology. J. Phillipson (ed.) UNESCO/IBP, Genève, p. 139-143.

MIYAZAMA, M., PAV́AN, A. £ BLOCH, N.S.M. 1984. Avaliação de métodos com e sem digestão para extração de elementos em tecidos de plantas. Cienc. Cult. 36: 1953-1968.

OLIVEIRA, R.R. 1987. Produção e decomposição de serrapilheira m n Parque Nacional da Tijuca - RJ. Dissertação de Mestrado. Rio de Janeiro, UFRJ.

PROCTOR, J. 1983. Tropical forest litterfall. 1. Problem of data comparison. In: Tropical Rain Forest: Ecology and Management. Blackwell Scientific Publications. Oxford., p. 267-274.

SILVA FILHO, E.V. £ OVALLE, A.R.L. 1984. O papel da vegetação na neutralização da chuva ácida no Parque Nacional da Tijuca, RJ. Sem. Reg. Ecol. IV: 353-373.

SNEDECOR, G.W. £ COCHRAM, W.G. 1967. Statistical Methods. Iowa State Univ. Press. Ames, Iowa

SNYDER, L.J. 1967. Determination of trace amounts of organic lead in air. Anal. Chem. 39: 591-595.

STRUFFALDI-DE VUONO, Y., LOPES, M.I.M.S. £ DOMINGOS, M. 1984. Poluição atmosférica e elementos tóxicos na Reserva Biológica do Instituto de Botânica, São Paulo, Brasil. Revta. brasil. Bot. 7: 149-156.

STRUFFALDI-DE VUONO, Y. £ MARZOLLA, M.C. 1984. Decomposição da serrapilheira nas proximidades de uma siderúrgica. Anais IV Congr, SBSP. 83-86.

TRINDADE, H.A., PFEIFFER, W.C., OLIVEIRA, A.E., LONDRES, H. £ COSTA-RIBEIRO, C., 1981. Concentraçōes atmosféricas de total de partículas em suspensão e metais na cidade do Rio de Janeiro. Cienc. Cult. 33: 996-1005.

WARREN, H.V. £ DELAVAUT, R.E. 1962. Lead in some food crops and trees. J. Sci. Food Agric., 13: 96-98.

- WORLD HEALTH ORGANIZATION. 1977. Lead. Environmental Health Criteria 3. Genève. 